1996-01-01

\title{
A new high pressure sapphire nuclear magnetic resonance cell
}

Shi Bai

stevebai@gmail.com

Craig M. Taylor

Charles L. Mayne

Ronald J. Pugmire

David M. Grant

Follow this and additional works at: https://scholarsarchive.byu.edu/facpub

Part of the Biochemistry Commons, and the Chemistry Commons

\section{Original Publication Citation}

Bai, Shi, Craig M. Taylor, Charles L. Mayne, Ronald J. Pugmire, and David M. Grant."A new high pressure sapphire nuclear magnetic resonance cell." Review of Scientific Instruments 67 (1996): 24-243.

\section{BYU ScholarsArchive Citation}

Bai, Shi; Taylor, Craig M.; Mayne, Charles L.; Pugmire, Ronald J.; and Grant, David M., "A new high pressure sapphire nuclear magnetic resonance cell" (1996). Faculty Publications. 682.

https://scholarsarchive.byu.edu/facpub/682 


\title{
A new high pressure sapphire nuclear magnetic resonance cell
}

Shi Bai

Department of Chemistry, Brigham Young University, Provo, Utah 84602

Craig M. Taylor

Los Alamos National Laboratory, Los Alamos, New Mexico 87545

Charles L. Mayne, Ronald J. Pugmire, and David M. Grant

Department of Chemistry and Chemical and Fuels Engineering, University of Utah, Salt Lake City, Utah 84112

(Received 15 May 1995; accepted for publication 5 July 1995)

\begin{abstract}
A new version of a single-crystal sapphire high pressure nuclear magnetic resonance (NMR) cell is described that is capable of controlling the sample pressure independent of the temperature. A movable piston inside the cell adjusts and controls the sample pressure from ambient conditions to $200 \mathrm{~atm}$ within $\pm 0.3 \mathrm{~atm}$. The linewidth at half-height for a ${ }^{13} \mathrm{C}$ spectrum of carbon dioxide at $15{ }^{\circ} \mathrm{C}$ and $57.8 \mathrm{~atm}$ is found to be $0.5 \mathrm{~Hz}$. The carbon dioxide gas/liquid phase transition is clearly observed by measuring ${ }^{13} \mathrm{C}$ chemical shifts as the sample pressure approaches equilibrium. The time required for this NMR cell to reach equilibrium with its surroundings is relatively short, usually 15-30 min. The cell body has the same outer dimensions of a standard spinning turbine and fits into a standard $10 \mathrm{~mm}$ commercial probehead capable of controlling the sample temperature using the spectrometer's variable temperature unit. The flexibility of the device and the increased speed in making the measurement is demonstrated. Such control of important thermodynamic variables facilitates the NMR study of important biochemical and chemical reactions in gas, liquid, and supercritical fluid environments. (C) 1996 American Institute of Physics. [S0034-6748(95)03710-1]
\end{abstract}

\section{INTRODUCTION}

Supercritical fluid extraction (SFE) is now a promising technique in a variety of fields, e.g., the food industry, biochemistry, environmental control, and fuels engineering. ${ }^{1}$ While the number of applications involving supercritical fluids has continually increased, many details of the molecular behavior in the supercritical state are still lacking. Nuclear magnetic resonance (NMR) spin relaxation studies ${ }^{2}$ have proven to be very useful in exploring molecular dynamics in liquids and efforts have been made by Jonas and co-workers ${ }^{3}$ and Evillia et $a l^{4}$ to use NMR spin relaxation methods for investigating molecular rotational motion and transport properties of molecules dissolved in supercritical carbon dioxide and ethylene. In spin relaxation studies of carbon dioxide, Etesse and Kobayashi et al. ${ }^{5,6}$ measured the ${ }^{13} \mathrm{C}$ spin-lattice relaxation time in the vicinity of the carbon dioxide critical point. ${ }^{6}$ Recently, density dependent chemical shift measurements at high pressure were made by Yonker and co-workers ${ }^{7}$ for exploring the fluid structures in supercritical xenon.

Two basic approaches, ${ }^{8,9}$ referred to as the high pressure probe technique $e^{9-12}$ and the high pressure cell technique ${ }^{13-15}$ have been utilized in high pressure NMR studies. A high pressure probe usually offers higher sensitivity because of a better filling factor for the receiver coil and generally allows for studies at higher pressures, but this approach involves additional complexity in the experimental design and operation. The high pressure cell has the advantage that it is ready for use in a commercial probehead without the necessity of altering the basic probe design. Unfortunately, this second method usually experiences lower sensitivity and reduced pressures. A careful consideration of these two options indicates that the second choice provides a more convenient and cost-effective means for carrying out NMR experiments whenever pressures are limited to several hundred atmospheres and when sensitivity is adequate. In this paper a new sapphire high pressure NMR cell that can control both the sample pressure and temperature independently is described and some experimental results are discussed.

The most recent efforts on high pressure cells for supercritical fluids (SCF) were reported by Yonker et al. ${ }^{15}$ where a fused silica capillary tube is coiled inside a commercial 5 $\mathrm{mm}$ NMR tube for high pressure NMR measurements. This design provides a simple and safe method of obtaining NMR spectra at high pressure when inner surface effects of the capillary tube are negligible. Roe ${ }^{13}$ first suggested a singlecrystal sapphire tube as the sample holder in a high pressure NMR cell. Horváth and Ponce ${ }^{14}$ then proposed an alternative design that was easier to fabricate and operate. This latter design avoids the use of a needle valve and permits one to introduce a solid sample directly into the cell while minimizing the risk of leakage common to needle valves. However, these earlier designs have no provision for controlling the sample pressure in the cell once the cell has been placed in the magnet. Furthermore, these cells place a considerable amount of the sample outside of the NMR detection coil and beyond the range of effective temperature control. Both conditions are detrimental to spin relaxation studies in gases and in supercritical fluids because the polarized spins may diffuse in and out of the coil during the relaxation's evolution time. Consequently, the signal recovery in an inversion recovery experiment is dependent, at least in part, upon diffusion unrelated to intrinsic spin relaxation.

The sample pressure in our sapphire tube is controlled 
with a movable piston inside the cell body. The precision of the pressure adjustment depends on the accuracy of the two pressure pumps that are connected to the sample chamber and to a separate pressure control chamber that governs the movable piston. In this work, the pressure control is about $\pm 0.3 \mathrm{~atm}$ and the probe temperature control unit sets the temperature at about $\pm 0.5^{\circ} \mathrm{C}$. With this tight control of pressure and temperature, the gas-liquid phase transition of carbon dioxide may be successfully observed by measuring the chemical shift of carbon dioxide as the carbon dioxide in the sample chamber comes into equilibrium with the pressure control chamber.

\section{EXPERIMENT}

\section{A. The new high pressure sapphire NMR cell}

A schematic drawing of the sapphire high pressure cell, consisting of a titanium cap (a), piston cylinder (b), and sapphire tube (c), is shown in Fig. 1. The 10-mm-o.d. sapphire tube $^{16}$ with a wall thickness of $1.3 \mathrm{~mm}$ is mounted to the piston cylinder with a two component epoxy adhesive. ${ }^{17}$ The titanium alloy cap has two connectors [(d) and (e)] that connect the cell to a pressure pump and a sample source pump, respectively. One of these connectors (e) links the sample source to the top of a movable piston (f) within the sapphire cell through a $100 \mu \mathrm{m}$ capillary tube (h) which is coiled inside the titanium cap. After introducing the sample, this connecting capillary line is closed by a valve outside of the cell. A pressure transducer monitors the sample's pressure inside the sapphire tube. The second connector (d), directly linked to the pressure pump, provides the driving force for the movable piston (f) mounted in the piston's cylinder (b) by two viton o-rings (i). If there is a differential pressure between the sample and driving compartments, the piston will move along the cylinder in order to equalize the pressure on both sides of the piston. The other function of the piston is to isolate the driving fluid from the sample under investigation. A press fit Tefzel plug (g) with a microcapillary opening $(50 \mu \mathrm{m})$ through the plug is inserted into the sapphire tube to restrict the sample volume within the NMR detection coil and to minimize mixing of the sample fluid with the fluid in the head space between the plug and the piston. This feature allows one to eliminate errors arising from diffusion between polarized and nonpolarized spins. This method also has better temperature control of the sample that is within the rf coil surrounding the sapphire tube, thereby minimizing thermal convection. The spaces below and above the plug are called the observation chamber $(\mathrm{m})$ and the antechamber (n), respectively. It is presumed that the pressures in the antechamber (n) and the driving chamber (o) rapidly equilibrate through the movable piston (f), capable of traveling a distance of $5 \mathrm{~cm}$, providing the piston is not locked at one of its extreme positions. An o-ring (k) isolates the sample from contact with the glue (1) used to attach the sapphire tube to the piston cylinder.

The outside dimensions of the cell body are the same as those of a standard spinning turbine except that the titanium cap is longer than the corresponding part of the turbine. With this design, it is not possible to spin the cell while it is

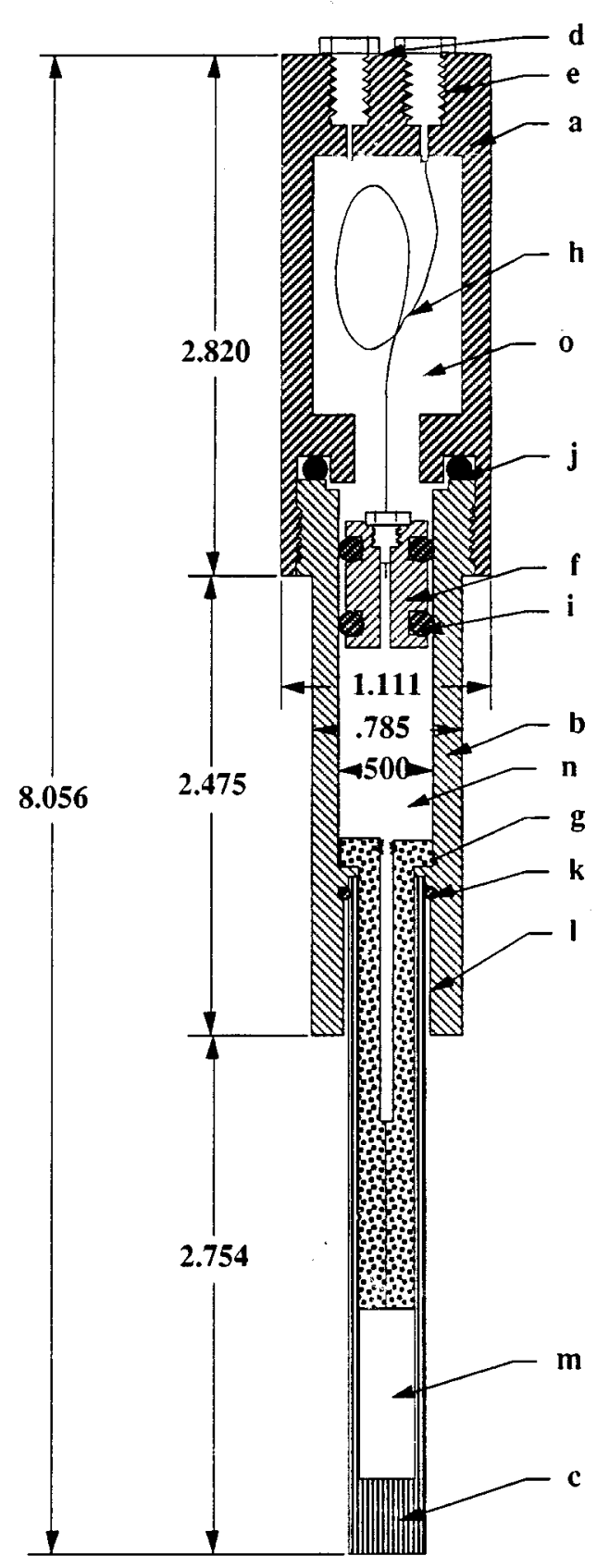

FIG. 1. Schematic diagram of NMR high pressure sapphire cell: (a) titanium cap, (b) piston cylinder, (c) sapphire tube, (d) connector to pressure generator, (e) connector to sample source, (f) movable piston, (g) Tefzel plug, (h) capillary tube, (i) piston o-ring, (j) o-ring to seal (a) and (b), (k) o-ring to separate glue from fluid under investigation, (l) glue clearance, $(\mathrm{m})$ observation chamber, (n) antechamber, and (o) pressure control chamber.

connected to the pressure pumps, but diffusion within the sample chamber still continues to narrow the NMR peak especially for gases and supercritical fluids. When the cell is assembled, the capillary tube is connected to the piston by a $1 / 32$ in. Valco nut through a short section of a Peek tube (1.5 cm, 1531B, Upchruch Scientific Inc., Oak Harbor, WA). The piston is inserted into the cylinder with excess capillary tubing projecting through the hole for connector (e) before the titanium cap is tightened on the cylinder. The open end of the capillary tubing is then carefully inserted through the hole 
for connector (e) by $5 \mathrm{~cm}$ and sealed by another short Peek tube and a 1/16 in. Valco nut to connector (e) as indicated.

\section{B. Cell operation}

Before each measurement, the cell is evacuated for at least $12 \mathrm{~h}$. A fluid, such as carbon dioxide, is first introduced into the sapphire cell by the sample pump. Liquid or solid samples must be transferred into the sapphire cell before assembly. A gas sample can be mixed inside the sample pump before it is pumped into the cell. The driving fluid is then gradually pumped into the pressure control chamber inside the titanium cap, transmitting the pressure to the antechamber through the movable piston until the desired pressure is achieved inside the observation chamber.

Safety considerations are of paramount importance in the use of a sapphire cell. The pressurized cell is always placed behind a safety shield during the sample handling, and laboratory personnel should never be exposed directly to the pressurized tube. The sapphire tubes are essentially chemically inert, but their single-crystalline nature makes them sensitive to minor vibration and scratches. One is therefore cautioned in the use of a hydrosonic bath as a means to mix samples. After reducing the cell pressure, it usually takes about $4 \mathrm{~h}$ for the carbon signal to completely disappear. Thus, at the conclusion of each experiment, the cell is vented slowly and, as an operational procedure, the cell is left over night in an open tube status to assure that all high pressure regions of the cell have been completely equilibrated before the cell is disassembled. Fragile cell components dictate that it should never be disassembled until it is completely depressurized. Fortunately, the total amount of sample within the probe is relatively small even for the highest attainable pressures, and the stored energy within the cell rapidly dissipates in the event of cell breakage.

\section{RESULTS}

\section{A. Mechanical properties}

The pressure changes induced by the movable piston inside the cell body have been evaluated in the liquid and vapor states of carbon dioxide. After the sample cell is filled with carbon dioxide at room temperature, the driving fluid, also $\mathrm{CO}_{2}$, is introduced and compresses the sample by moving the piston through its maximum travel range. When the initial pressure of carbon dioxide is $58 \mathrm{~atm}$, the pressure control range associated with the moving piston is about 10 atm.

This pressure control range increases to over $100 \mathrm{~atm}$ when the initial pressure is $100 \mathrm{~atm}$. The coarse pressure adjustments require simultaneous manipulation of both the sample source and driving pressure pumps. Fine pressure adjustments generated by the traveling piston have been found to be adequate for our NMR experimental applications.

\section{B. ${ }^{13} \mathrm{C}$ NMR spectra}

A ${ }^{13} \mathrm{C}$ spectrum of carbon dioxide in the liquid state $\left(15^{\circ} \mathrm{C}\right.$ and $\left.57.8 \mathrm{~atm}\right)$ is given in Fig. 2 to indicate the mag-

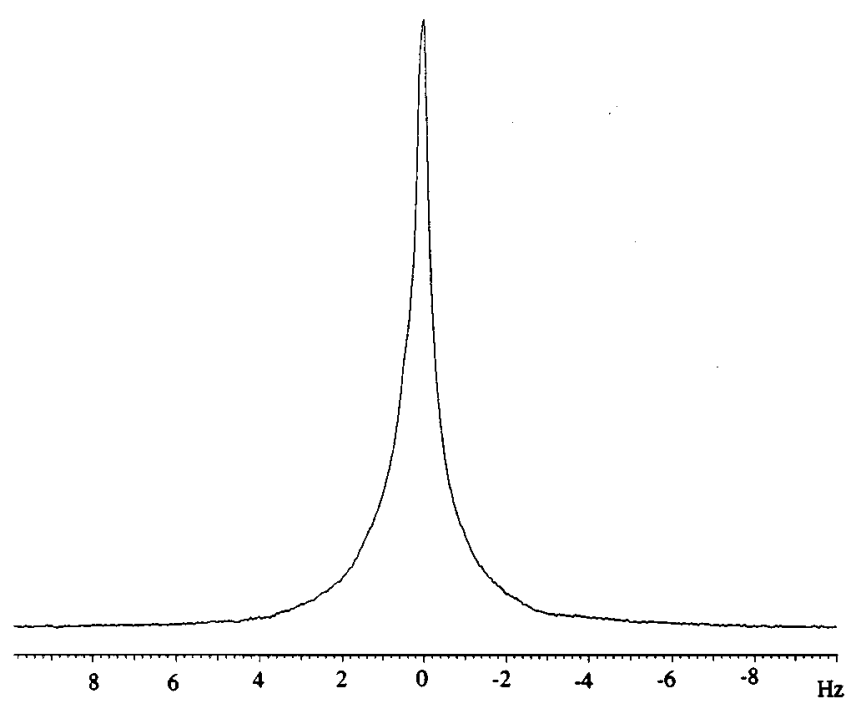

FIG. $2 .{ }^{13} \mathrm{C}$ spectrum of carbon dioxide in the liquid state $\left(15^{\circ} \mathrm{C}\right.$ and 57.8 $\mathrm{atm})$, illustrating magnetic field homogeneity across the sample.

netic field homogeneity attainable within the sample cell. The line width at half-height was found to be $0.5 \mathrm{~Hz}$, but the line width at $0.5 \%$ peak height was $11 \mathrm{~Hz}$ to be compared with the $1-2 \mathrm{~Hz}$ observed on a standard liquid sample in a spinning commercial glass tube. These data are similar to those reported by Roe. ${ }^{13}$

\section{Carbon dioxide phase transitions}

To calibrate our experimental device for controlling pressure and temperature, the $\mathrm{CO}_{2}$ phase transition has been explored by observing the change associated with the ${ }^{13} \mathrm{C}$ chemical shifts. Figure 3 shows a gas-liquid transition of carbon dioxide observed in this cell. Starting with an initial condition of $20.3{ }^{\circ} \mathrm{C}$ and $56.5 \mathrm{~atm}$ assures that the $\mathrm{CO}_{2}$ begins in the vapor state. The pressure in the pressure control chamber (o) is then increased to $57.3 \mathrm{~atm}$ and then sequential

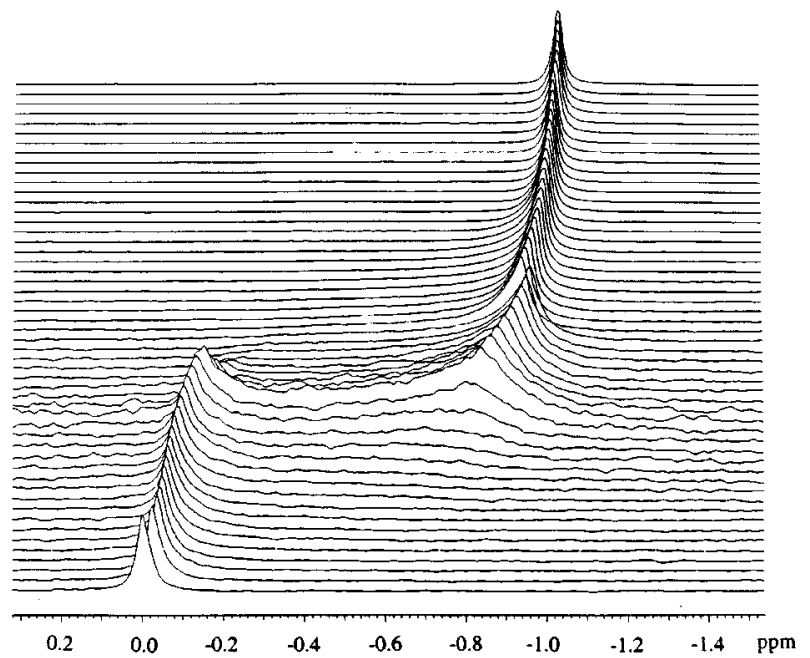

FIG. 3. Vapor-liquid phase transition of carbon dioxide below the critical temperature as the sample pressure equilibrates with the pressure control chamber. The chemical shift for carbon dioxide in the vapor state is arbitrarily assigned at $0 \mathrm{ppm}$ and changes by about $-1 \mathrm{ppm}$ in the phase transition to the liquid state. 


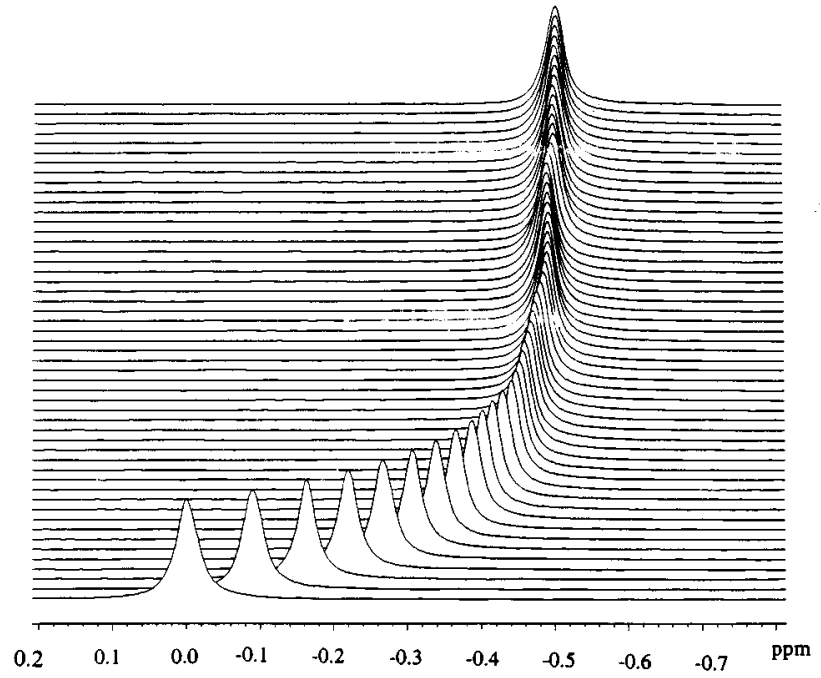

FIG. 4. The pressure dependence of the chemical shifts of carbon dioxide above the critical temperature as the pressure increases to exceed the critical pressure. The chemical shift varies continuously as one passes from the gaseous to the supercritical fluid state. The chemical shift for carbon dioxide in the vapor state is arbitrarily assigned at $0 \mathrm{ppm}$ and changes by about -0.5 $\mathrm{ppm}$ in the supercritical fluid.

spectra are acquired at $30 \mathrm{~s}$ intervals. Transition between the vapor and liquid states is clearly observed in the observation chamber of the cell as the sample slowly increases to the new pressure. The spectra in Fig. 3 indicate that the carbon dioxide in the cell started in the vapor state, exhibited vapor and liquid in equilibrium after about $6 \mathrm{~min}$, and finally was totally converted into the liquid state shortly thereafter. The reverse process, the liquid to vapor phase transition, followed a similar pattern.

The change in the chemical shift of gaseous carbon dioxide at a temperature $\left(37.7^{\circ} \mathrm{C}\right)$ above the critical temperature is also examined as the pressure passes through the critical pressure. The results are shown in Fig. 4. After an initial pressure is set at $72.1 \mathrm{~atm}$ and the first spectrum is taken, the pressure in the pressure control chamber is increased to 73.5 $\mathrm{atm}$. As one might expect, the chemical shift of carbon dioxide does not split into two components. A monotonic shift in the resonance position $(-0.5 \mathrm{ppm})$ is noted as the pressure increases in the observation chamber. It may be noted from Figs. 3 and 4 that it takes about $15 \mathrm{~min}$ for the system to reach equilibrium in the sample chamber after increasing the driving force in the pressure control chamber. This ability to follow responses to changing pressures illustrates one of the advantages of using a small sample volume separated from the antechamber by a small capillary channel.

\section{Relaxation time measurements}

This cell was used to measure the ${ }^{13} \mathrm{C}$ spin-lattice relaxation times in carbon dioxide from 30 to $200 \mathrm{~atm}$ at nine isotherms ranging from 15 to $70{ }^{\circ} \mathrm{C}$. The results are comparable with those obtained by Etess et al..$^{5}$ indicating that the cell is able to control sample pressures and temperatures adequately for spin relaxation measurements over gas, liquid, and supercritical fluid densities.

\section{ACKNOWLEDGMENTS}

This work was supported by the Basic Energy Sciences at D.O.E. (Grant No. DE FG02-94ER14452) and by the Advanced Combustion Engineering Research Center at Brigham Young University/University of Utah. Funds for the Center are provided by the National Science Foundation (Cooperative Agreement No. CDR 8522618), the State of Utah, and 28 industrial and government participants. W. B. $\mathrm{Li}$ of BYU is acknowledged for participating in the sapphire NMR high pressure design and testing work.

${ }^{1}$ T. J. Bruno and J. F. Ely, Supercritical Fluid Technology-Reviews in Modern Theory and Applications (CRC, Boca Raton, 1991).

${ }^{2}$ D. M. Grant, C. L. Mayne, F. Liu, and T. X. Xiang, Chem. Rev. 91, 1591 (1991).

${ }^{3}$ D. M. Lamb, S. T. Adamy, K. W. Woo, and J. Jonas, J. Phys. Chem. 93, 5002 (1989)

${ }^{4}$ R. F. Evillia, J. M. Robert, and S. L. Whittenburg, J. Phys. Chem. 93, 6550 (1989).

${ }^{5}$ P. Etesse, J. A. Zega, and R. Kobayashi, J. Chem. Phys. 97, 2022 (1992).

${ }^{6}$ P. Etesse, A. M. Ward, W. V. House, and R. Kobayashi, Physica B 183, 45 (1993).

${ }^{7}$ D. M. Pfund, T. S. Zemanian, J. C. Linehan, J. L. Fulton, and C. R. Yonker, J. Phys. Chem. 98, 11846 (1994).

${ }^{8}$ I. T. Hotváth and J. M. Millar, Chem. Rev. 91, 1339 (1991).

${ }^{9}$ A. Zahl, A. Neubrand, S. Aygen, and R. van Eldik, Rev. Sci. Instrum. 65, 882 (1994).

${ }^{10}$ B. T. Heaton, J. Jonas, T. Egichi, and G. A. Hoffmann, J. Chem. Soc. Chem. Commun. 331 (1981).

${ }^{11}$ B. T. Heaton, L. Strona, J. Jonas, T. Egichi, and G. A. Hoffmann, J. Chem. Soc. Dalton Trans. 1159 (1982).

${ }^{12}$ J. W. Rathke, J. Magn. Res. 85, 150 (1989).

${ }^{13}$ D. C. Roe, J. Magn. Res. 63, 388 (1985).

${ }^{14}$ I. T. Horváth and E. C. Ponce, Rev. Sci. Instrum. 62, 1104 (1991).

${ }^{15}$ C. R. Yonker, T. S. Zemanian, S. L. Wallen, J. C. Lienhan, and J. A. Franz, J. Magn. Res. A 113, 102 (1995).

${ }^{16}$ Sapphicon Inc., Milford, NH 03055.

${ }^{17}$ Aremco-Bond ${ }^{\mathrm{TM}}$ 631, Aremco Products, Inc., Ossining, NY 10562. 